\title{
Reconsidering Esport: Economics and Executive Ownership
}

Authors' contribution:

A) conception and design of the study

B) acquisition of data

C) analysis and interpretation of data

D) manuscript preparation

E) obtaining funding

\section{Veli-Matti Karhulahti}

University of Turku, Finland

\section{ABSTRACT}

This article starts with a literary review of the conceptual frames through which esport has been labeled academically. It shows how the concept of "electronic" has been taken as the core term for labelingesport, often accompanied by a strong emphasis on "professionalism." The literary review is followed by the submission of an alternative conceptual frame based on the economic notion of executive ownership, which provides a theoretical grounding for esport as a cultural phenomenon. In accordance with the above, the article concludes with a reframed look at the history of esport and suggests commercial analog gaming (especially Magic: The Gathering) as its point of origin.

KEYWORDS

Esports, economics, games, theory, history, politics

\section{Introduction}

In the following, I shall offer a conceptual reframing and theoretical grounding for the recently popularized phenomenon known as esport. My contribution stands on three points of analysis.

Initially, I will provide a literary review of the frames through which researchers have labeledesport thus far. The review implies that the concept of "electronic" has been taken as the core term for labelingesport, often accompanied by a strong emphasis on "professionalism." Subsequently, I offer an alternative conceptual frame that employs the economic notion of executive ownership as a theoretical ground for esport as a cultural phenomenon. As a supporting case study, I scrutinize a current event concerning the absolute power that one of the leading executive esport owners, Riot Games, has applied. I conclude with a reframed look at the history of esport and suggest commercial analog gaming as its point of origin.

My general position is as follows: instead of perceiving esport as sportified electronic gaming, it might be more practical to perceive it as sportified commercial gaming. Esports are cultural practices of exercise and contest on commercial play products that are governed by executive owners.

\section{Perspectives on esport}

English academic observations on esport started to appear in the 2000s (e.g. Mora \& Héas 2003, Kushner 2004, Lee 2005). The first serious attempt to identify the phenomenon was Dennis Hemphill's article in the 
Journal of the Philosophy of Sport entitled "Cybersport" (2005), which he used as a reference to "alternative sport realities, that is, to electronically extended athletes in digitally represented sporting worlds" (p. 199). A decade later, Hemphill rearticulated the above into "electronically extended human actions in computermediated or -generated sporting worlds" (2015, p. 346). His position reflects well the general sentiment by tying "electronically extended" to the traditional "sporting" ideal (see also van Hilvoorde 2016, Holt 2016, van Hilvoorde \& Pot 2016).

Michael Wagner's article from 2006 defines esport as "an area of sport activities in which people develop and train mental or physical abilities in the use of information and communication technologies" (p. 3; cf. Wagner 2007, Martončik 2015, Al Dafai 2016). What is exceptional in Wagner's definition is the way in which the 'e' of esport does not get explained by the conventional keywords "electronic" or "computerized," but instead information and communication technologies. This leaves space for evolutionary transformation, whilst simultaneously erecting limits that few established sports cross.

After the writings of Hemphill and Wagner esport began to proliferate extensively, resulting in increased academic interest. Most of the subsequent studies have delineated their research object according to the previously-set margins. While Jane Rambuschet al (2007) talk about "competitive gameplay which borrows forms from traditional sports" (p. 157), Thomas Weiss $(2008,2011)$ conceives of esport as "playing competitive games according to generally accepted rules of leagues and tournaments on the Internet" (p. 572). KalleJonasson and JesperThiborg (2010) consult official sources that see esport as "sport within and through the medium of cyberspace, as the new upcoming sport and as competitive (professional) video or computer gaming” (p. 288). Along the same line, Marcella Szablewicz (2011) asserts:

"Broadly speaking, E-Sports involves a number of different game genres including first person shooters, sports games, racing games, action games and real time strategy games. These games are played competitively, either one-on-one or in small teams. Importantly, games usually gain acceptance as ' $E$-Sports' once they have been selected for official inclusion in an international E-Sports competition” (p. 9; see also Szablewicz 2016).

In Janina Maric's (2011) work, esport stands for "organised and competitive video gaming” (p. 6), not unlike Ilya Ryzhov et al (2011), who use the words "competitive online gaming" (p. 4234; cf. Parshakov \& Zavertiaeva 2015, Kauweloa \& Winter 2016). Emma Witkowski (2012a) has esport as "an organized and competitive approach to playing computer games" (p. 350; also 2012b), whereas William Hamilton et al (2012) use the concept for "high-level play and spectating of digital games" (p. 310). Nick Taylor (2012) frames esport as "the world of professional videogame play" (p. 251; also 2011, 2015), while Oscar Bornemark (2013) considers it "a general term to describe the play of video games competitively" (p. 1).

In the cultural context of China, Zhang Guorui (2012) labels the activity as one that employs "high-tech hardware and software devices as sports equipment, and is an intellectual confrontation sport between people" (p. 111; cf. Dongsheng et al 2011, Ma et al 2013). Eui-Yul Choi (2013), in turn, makes use of definitions that were put forward in Korea:

The Korean eSports Association (KeSPA) defined eSports as a leisure activity within cyberspace in which participants matched their electronic game skills against each other for win or loss ... Lee and Ko defined eSports as a match among human players using electronic games through Local Area Networks (LAN's) or the Internet (p. 10; see also Kim et al 2012, Kim 2013, Lee et al 2014).

Studies in law repeat the pattern by introducing esport with brief descriptions like "professional gaming tournaments" (Comerford 2012, p. 624), "professional video gaming" (Rothman 2013, p. 317), and "professional gaming" (McTee 2014, p. 2). Longer descriptions speak of "computer games [with players] intent on making a living" (Burke 2013, p. 1536) and "professional video game matches where players compete against other players before an audience" (Hollis 2015, p. 825; see also Karhulahti 2016, Holden et al 2017). At the time of writing, the most recent definition comes from JuhoHamari and Max Sjöblom (2017):

"We define eSports as a form of sports where the primary aspects of the sport are facilitated by electronic systems; the input of players and teams as well as the output of the eSports system are mediated by human-computer interfaces" (Hamari \& Sjöblom 2017, p. 5). 
In the presented legion of more and less comparable viewpoints, Brett Hutchins' (2008) report on the then-current World Cyber Games (WCG) organization is a relevant exception. He questions the utility of the term "sport" not only as a descriptive concept but also as a historical point of reference, opening up an interesting analytical perspective:

“The pliability of the term 'sport' appears to negate the need for a new term such as e-sport. To think in these terms misreads the subject matter and ignores the distinctive and defining feature of the WCG and competitive gaming, which is something no sport shares: the material interpenetration of media content, sport and networked computing” (Hutchins 2008, pp. 863864).

Indeed, esport is rich in its forms and features, perhaps to the degree that associating it with the traditions of 'professional sport' does more harm than good. While many scholars have probed these associations (see Taylor 2009, Lee \& Schoenstedt 2011, Hebbel-Seeger 2012, Ferrari 2013, Stein \& Scholz 2014, Hewitt 2014, Kari \& Karhulahti 2016, Nagel \& Sugishita 2016, Seo 2016), the nine years between Hutchins' report and the review at hand reveal how the phenomenon has come to imitate its assumed archetype - the Western ideal of professional sport - more than it differs from it. With its refined leagues, live broadcasts, collegiate programs, and growing doping control, the core of contemporary esport is, unquestionably, in the aspects that derive from professional sports.

To summarize, contemporary academics seem to have a shared conceptual frame for labeling esport. With nuance, they all perceive esport through two criteria: technological specificity (computers, cyberspace, electronics) and advanced competition (athleticism, professionalism, sport). These criteria are directly connected to the videogame culture so that esport is recognized as an "extension of gaming."

It cannot be stressed enough that the conceptual frame in question is merely the descriptive (semitheoretical) label, and it does not represent the range of research that has been done on esport. Many of the referenced scholars are well aware of the multiplicity of esport as a cultural phenomenon (including its economic foothold), and the quoted micro-descriptions function merely as labels for their in-depth research. Regardless, the conceptual economic frame that is introduced below has not yet been discussed as an explicit basis for a theory, which makes addressing the following perspective academically relevant.

\section{Economic Perspective}

My aim in the present section is not to initiate terminological or definitional revolution, but to explain the specificity esport in the histories of technology and sport a bit better than the rhetoric of "electronic" and "professional" does. This aim is analytically motivated in part, as I believe it also provides a realistic ground for discussing esport in the context of theory.

The economic perspective on esport starts from this premise: what makes esport a unique instance of competitive culture is its commercially developed, distributed, and maintained artifact of play. Unlike the majority of previously established and recognized sports, esport operates on gaming systems that have been designed as commercial products by profit-making companies. While academics have certainly noticed and analyzed these features as critical components of the phenomenon - T.L. Taylor (2012) must be mentioned specifically - none have structured them theoretically to explain esport as a radical instance of economic sport (and media) evolution. It is fitting to start by pointing to some basic elements in three historically noteworthy esport products.

The real-time strategy title StarCraft is usually considered as the first major esport. It was developed and published in 1998 by Blizzard Entertainment, utilizing the traditional pay-once monetizing method. To play StarCraft, one needs to buy a copy of it via a physical or digital retailer. Ultimately, StarCraft became a commercial success by selling nearly ten million copies. It is generally documented as the product that shaped esport into its present form (see Huhh 2008, Jin 2010, Chee 2012, Groen 2013, Felczak 2015). Technically speaking, StarCraft turned out to be a trailblazing platform for competition because of its player-versus-player mode that enabled built-in contests. Among other factors of its success, Blizzard Entertainment chose to distribute StarCraft with a feature called "spawning," which allowed the player-versus-player mode to be 
played by multiple players with a single retail copy. The sequel StarCraft 2 (2012) took its predecessor's place in the esport scene after its release (see Korean Creative Content Agency 2013).

Another still-vibrant early esport is the team-based first-person game Counter-Strike. It was first developed as a non-commercial mod for the videogame Half-Life (Valve Corporation 1998) in 1999 by Minh Le and Jess Cliffe. Soon after the mod's release, Valve Corporation acquired its intellectual property rights and hired both of the original creators. Counter-Strike was published commercially in 2000, subsequently gaining several updates and installments, of which Counter-Strike: Global Offensive (2012) is currently the most popular one. Counter-Strike follows the business strategy of StarCraft by selling the product in retail stores.

The third example is League of Legends, a team-based game that was developed and published commercially in 2009 by Riot Games. League of Legends has its roots in modding culture too, being a derivative of a fan-made mode for Warcraft 3 (Blizzard Entertainment 2002). Unlike StarCraft and CounterStrike, this esport can be played without retail purchase. League of Legends employs a monetization method that relies mainly on decorative virtual item sales that do not affect competitive play performance (see monetization methods in Lehdonvirta \& Castronova 2014). Similar economic principles govern other major esport products, such as Dota 2 (Valve Corporation 2012), as well.

The key point here is that (regardless of their origins in independent modding culture) each of the above esport products has ultimately been developed, distributed, and maintained by a profit-making company. While some of them can be played without purchase or registration fees, all of them have been expanded and updated by their owners to make financial profit. If the product becomes financially unprofitable, as occasionally happens, it ceases to maintain its status as a sport. The relationship between an esport product and its profitmaking owner is thus significantly different from that between any traditional sport and its governing institution (or sponsor). The relationship between esport products and their profit-making owners is not merely a spin-off from sport business and media markets, but a new technologically determined philosophy and politics of sport. The section below elaborates on this position by explaining the state of esport within the global sports sphere.

\section{Executive ownership}

The vision of sport as an autonomous, "pure" recreation has an interesting chapter in Western history (e.g. Weiss 1969, Hyland 1990, Connor 2011). While still unconsciously maintained by many, few openly fight against the reality of what is often referred to as the "sports-media complex," i.e. the interdependence of sport organizations, media conglomerates, sponsors, and athletes. As KatrienLefever's (2012) descriptive analysis shows, "sport has put the sponsors and media companies in a powerful position to dictate the characteristics of events or indeed, even to change fundamental aspects of the sport" (p. 9).

In esport, the complex is even more complex. The esport media complex is dominated by executive owners: companies that maintain the products (StarCraft2, Counter-Strike, League of Legends) on which the complex runs. An executive owner is much more than an interdependent component; it literally (re)writes the rules of its game, supplies the essential technology, and ultimately decides on the existence of the sport as a whole. While it is tempting to compare executive esport owners (Blizzard Entertainment, Valve Corporation, Riot Games) to powerful sport organizations like the FédérationInternationale de Football Association (FIFA), closer examination reveals their roles are utterly different.

While many of the leading sport organizations identify themselves as non-profit organizations, the notion of "non-profit" is a contested area. FIFA's (2016) self-proclamation confirms: FIFA is a not-for-profit community of 209 football associations. FIFA's financial health is vital for global football.

An executive owner, on the other hand, is an openly profit-making institution, usually a game development company. Most of these companies manage several esport (and other) products at once. The esports that executive owners govern belong to their business models, which demarcate the ways in which the products get developed, distributed, and maintained. 
The development process of an esport product might bear some similarity to today's popular sports. As presented above, many of the current esport products originated as non-commercial software artifacts in the hands of creative fans and enthusiasts. The software artifacts were later acquired by profit-making companies, refined into commercial products, and sold via retail or accompanied by in-game purchases. Both development and distribution emerge under the surveillance of profit.

One could argue that the same happens all the time in traditional sports when major institutions make use of existing game structures. Ice hockey, for instance, has been developed and modified into commercial products like the National Hockey League (NHL) in North America. While the basic rules remain faithful to the sport's roots, occasional changes occur (often in accordance with pleasing the paying spectator), such as the addition of excitement-enhancing shootouts. Ultimately, media collaborators control the consumption of the product by providing access to the spectacle through limited channels. And yet, all this still differs critically from the standards of esport, the business of which has been shaped distinctively by its executive ownership.

Firstly, despite the existence of numerous commercialized ice hockey institutions, one can play ice hockey whenever one desires, even with NHL rules. The principle does not apply to contemporary esport products, many of which operate under online servers that are hosted by their executive owners. In the case of technical, political, or financial trouble, StarCraft2, Counter-Strike, and League of Legends may and do become unplayable. Executive ownership enables the governing company to regulate (and collect data about) the playing of their sport.

Secondly, executive ownership puts the governing company into an exceptional position in terms of organized competition. Perhaps the most well-known example is the conflict between the Korean Esports Association (KeSPA) and Blizzard Entertainment (the executive owner of StarCraft). T.L. Taylor's (2012) documentation of the event is an illustrative reference here, describing how Blizzard Entertainment's technical authority over the product enabled them to regulate its use in official tournament play and broadcasting. Ultimately, intellectual property rights and the licensing of esport products "takes place not just around games themselves but the tournament or organization brand" (p. 160). This allows companies like Blizzard Entertainment to make "very specific decisions about how tournament play should unfold" (p. 164).

Thirdly, the executive ownership of esports includes the financial responsibility to keep the products playable and up-to-date. There is much more in such maintenance than mere server upkeep and regular bug fixing: in order to hold the interest of playing and paying customers, executive owners need to keep on redesigning their esport endlessly. Through what could be called patch-metagame cycles, governing esport companies modify their games significantly up to twice per month, thus making sure that devoted players always have new strategies to work with (and new ornaments to purchase). The behavior of active players which gets constantly collected into big data (see Egliston 2016) thanks to server-based online technology - is obviously a critical factor in the frequently occurring patching that results in a symbiotic cycle between the ongoing actions of esport players and their governing companies.

While the above observations mainly rely on the fact that esport play is, indeed, strongly based on electronic artifacts, perhaps even more fundamental for their cultural and historical identity is the exceptional economic foundation that regulates them. Esport is a cultural practice of exercise and contest on commercial play products that are governed by executive owners. The next section provides a case study that illustrates the theoretical distinctiveness of the above-specified conceptual frame.

\section{Absolute power}

This chapter provides a reading of a recent sequence of events that led to perhaps the most severe personal punishment(s) in esport history so far. The events concern the actions of Christopher Mykles and Chris Badawi, who were affiliated with Renegades, a League of Legends team. Their actions were judged by the executive owner of the esport in question, Riot Games. The context of the case extends back to June 2015, as Riot Games decided to penalize Badawi, a co-owner of the Renegades team at the time, for poaching Team Liquid's Diego Ruiz and Yuri Jew:

"Chris Badawi ... solicited a player under contract with Team Liquid to join his team. After

doing so he was notified by Team Liquid's owner and LCS officials that soliciting LCS players 
under contract was a violation of league tampering rules and could disqualify him for consideration as an owner, coach, or player. Despite the warning, he again tampered with another Team Liquid player shortly thereafter. Due to this pattern of willful tampering, we are declining to certify Chris Badawi as an eligible LCS owner and issuing a one-year ban on him holding any officially recognized team position in Riot-affiliated competition" (Riot Games 2015).

Riot Games thus passed a ban on Badawi, disallowing him from owning a team until summer 2016. As a result of the ban, Renegades had to find a new owner. After securing their spot for the upcoming season, Renegades incorporated under a new company, Mykles Gaming LLC, which was solely owned by Christopher Mykles. The Season 2016 started without a problem for Renegades team - until May 9, when Riot Games announced a new ruling on their official esports site:

"We have been provided with evidence that current Renegades owner Christopher Mykles had a deal in place with suspended former owner Chris Badawi that would grant Badawi a 50\% stake in the team once his suspension had expired. Per LCS rules, any present or future right to ownership is considered a firm ownership ... Both the Renegades organization and TDK organization will no longer be allowed to continue participating in Riot-sanctioned leagues. In addition, Chris Badawi will be permanently banned from association or affiliation with any team or organization participating in a Riot-sanctioned league, while Christopher Mykles is banned for one year from holding any Riot-sanctioned position" (Riot Games 2016a).

What makes the above rulings interesting for the present study is the executive owner's use of its absolute power. When Riot Games operates as the investigator, prosecutor, and judge, there is little room for external examination or influence when it comes to the unavoidable complications that follow in all sports. Fittingly, the situation got heated a month after Riot Games' statement, as one of the penalized parties, Mykles, published a 70-minute video report on YouTube claiming that the deal Riot Games had (mainly) based their judgment on was nonexistent, and the accusations were false:

"I made no promises to give up any part of my team. I never said that, ever, to anyone. And the thing is, whatever evidence Riot [Games] has, it didn't come from me, I know that ... I own a $100 \%$ of my company; no one else can say what happens to my company, except for me. I didn't say it, therefore they cannot have solid evidence ... I have no idea what that claim was about." (Mykles 2016a)

Mykles supported his report by publishing several official and nonofficial documents as attachments (Mykles 2016b), such as his Participation Agreement, Company Agreement, email exchanges, and Skype conversations (with Riot Games). While the present article has no capacity or need to evaluate the accuracy of Riot Games' assertions or Mykles' defense - all of which were merely a part of the long chain of punishments that concerned several other parties and proclaimed violations - they do function as an expounding case of an executive owner exerting its absolute power in practice.

Due to Riot Games' superior control over its product technologically, economically, and politically, instances like this leave punished parties few options to make use of the proficiency that they have developed within the cultural practice in question. According to an estimate by ESPN (which might be biased due to one of their contributors being affiliated with the case), the ban passed by Riot Games "potentially cost the team and its two leaders ... millions of dollars of future revenue and sponsorship opportunities" (Wolf 2016). While in the present case the punishments did not bar the accused from all engagement with the game, this would have been possible and has happened in other circumstances (Riot Games 2016b). Since League of Legends runs on Riot Games' servers and the company organizes as well as oversees all higher-level competition, a ban can be a literal expulsion from a practice that has governed an individual's or organization's daily routines for years.

While similar instances can easily be found in traditional sports, Riot Games' executive ownership illustrates the historically unique identity of esport. A good counter-example can be made of the recent ban of Russian athletes that has no precedent in track and field or Olympics history. After the release of the World 
Anti-Doping Agency's investigative report on Russia (World Anti-Doping Agency 2015), several international sports federations, including the Olympics Committee, decided to ban the country from their major competitions (e.g. Mather \& Carey 2015, Ruiz 2016). This did not - and what is more critical here, cannot ever - prohibit any Russian athletes from practicing their sport themselves in their own country, in competitions outside corresponding international parties, or in willingly sponsored events. Since sports can only be administered, organized, and overseen (but never owned) by companies, the statuses of those sports cannot be compared to those of esport, which are defined by executive ownership.

\section{Rethinking esport history}

I have encouraged the reader to reconsider the "e" of esport by suggesting that the label term and theoretical basis for esport be "economic" (rather than "electronic"). For an organized competitive practice to be considered esport, it should rely on a commercial play product that is governed by an executive owner.

While this perspective should allow all presently thriving esport phenomena to maintain their cultural identity, it also enables some previously unclassified but culturally significant competitive practices to gain institutional recognition as esport. While several non-electronic esport-related institutions had already been established in the early 1990s and earlier - for instance, Avalon Hill's annual World Boardgaming Championships launched in 1991 (Boardgame Players Association 2016) - perhaps the most prominent example is the collectable card game Magic: The Gathering by Wizards of the Coast in 1993.

From the proposed theoretical perspective, Magic: The Gathering stands as the first large-scale phenomenon in esport history. Immediately after its release in 1993, the card game's executive owner, Wizards of the Coast, commenced organized tournament play under the supervision of its distinct organ of competition, Duelists' Convocation International. Sanctioned Magic: The Gathering play thus formed as an executively owned sport phenomenon long before the South Korean wave of professionalized StarCraft took off in the late 1990s.

The economic principles of Wizards of the Coast and their Magic: The Gathering precede and forecast quite accurately what was previously termed the patch-metagame cycle in contemporary esport. In the same way today's "electronic" esport products modify their gaming artifacts by providing frequent strategy-altering digital patches - hence keeping player-consumer masses engaged by offering them renewed content - Magic: The Gathering gets updated several times a year as new cards and changes are introduced to its official tournament rules. Unlike most of the presently thriving 'electronic' esport products whose profits derive mainly from one-time retail purchases (Counter-Strike: Global Offensive, StarCraft 2) or optional cosmetic purchases (Dota 2, League of Legends), Magic: The Gathering entails recurrent financial investments to its never-ending card expansions if the player wishes to remain qualified and competent (see Wizards of the Coast 2016).

While Magic: The Gathering can be played online as well, the analog format remains the version that defines its professional and social position (Trammell 2010). Regardless of the material overlap between noncommercial card and board games like chess and bridge, the executive ownership of Wizards of the Coast makes Magic: The Gathering an institutionalized competitive practice that is strikingly different from its essentially non-commercial peers. This practice can be considered structurally similar to electronic esport, with the caveat that the latter is more able to regulate their products materially, mostly thanks to the server-based nature of online technology and its media exposure.

\section{Conclusions}

Sport Accord (2015), currently the most authoritative international sport association, defines sport according to five criteria:

1. The sport proposed should include an element of competition.

2. The sport should not rely on any element of "luck" specifically integrated into the sport.

3. The sport should not be judged to pose an undue risk to the health and safety of its athletes or participants.

4. The sport proposed should in no way be harmful to any living creature. 
The sport should not rely on equipment that is provided by a single supplier.

When it comes to the ongoing negotiations concerning the cultural politics of esport and sport, the foremost conflict does not concern any of the oft-debated aspects of physicality, technology, or media-specificity, but rather executive ownership. Esport products are, without question, forms of sport as per their nature of competition, skill requirements, physical precision, and ethical aptness. However, what makes them challenging for the historians and theorists of sport (and media) is reflected in Sport Accord's fifth criterion: "The sport should not rely on equipment that is provided by a single supplier."

Esport, be it electronic or analog, always relies on a commercial play product that is governed by an executive owner. This raises several questions concerning the phenomenon's identity and status as a mediadependent competitive practice in the cultures and societies in which it endures. This article has been an attempt to uncover and discover those questions, with the hope that future discussion would put (even) more weight on the underlying principles of play that determine esport as an institutionalized player-driven activity.

\section{Acknowledgments}

This article was first presented as an invited lecture at the Finnish Conference of Game Studies on May 20, 2016. I thank all of my dozen reviewers over the past two years for their valuable feedback.

\section{REFERENCES}

Adamus, T. (2012). Playing Computer Games as Electronic Sport: In Search of a Theoretical Framework for a New Research Field. In J. Fromme \& A. Unger (Eds.), Computer Games and New Media Cultures: A Handbook of Digital Games Studies (pp. 477-490). New York, NY: Springer.

Al Dafai, S. (2016). Conventions within eSports: Exploring Similarities in Design. In Proceedings of the First International Joint Conference of DiGRA and FDG, 1-5 August 2016. Dundee, Scotland: Digital Games Research Association and Society for the Advancement of the Science of Digital Games.

Boardgame Players Association (2017). World Boardgaming Championships History. Retrieved April 13, 2017, from http://www.boardgamers.org/historyindex.html

Bornemark, O. (2013). Success Factors for E-Sport Games. In S. Bensch\& F. Drewes (Eds.), Umeå's $16^{\text {th }}$ Student Conference in Computing Science (pp. 1-12). Umeå: Umeå University.

Burk, D. (2013). Owning e-Sports: Proprietary Rights in Professional Computer Gaming. University of Pennsylvania Law Review Online, 161, 1535-1578.

Chee, F. (2012). Online Games as a Medium of Cultural Communication: An Ethnographic Study of Socio-Technical Transformation. Doctoral Dissertation, Simon Fraser University, Burnaby, Canada.

Choi, E. (2013). Investigating Factors Influencing Game Piracy in the Esports Settings of South Korea. Doctoral Dissertation, University of New Mexico, Albuquerque, New Mexico.

Connor, S. (2011). A Philosophy of Sport. London: Reaktion.

Dongsheng, Y., Xiaohang, Y., \& Daofeng, K. (2011). The Present Situation and Development Trend of E-sports Games in China. In Future Computer Science and Education Proceedings (pp. 384-386), 20-21 August. Piscataway, NJ: IEEE.

Egliston, B. (2016) Big Playerbase, Big Data: On Data Analytics Methodologies and Their Applicability to Studying Multiplayer Games and Culture. First Monday, 21 (7). DOI: http://dx.doi.org/10.5210/fm.v21i7.6718 [?

FédérationInternationale de Football Association (FIFA) (2016). Organization homepage. Retrieved April 13, 2017, from http://www.fifa.com/about-fifa/who-we-are/index.html

Felczak, M. (2015). Narratives of Spectatorship: E-sports in Poland. In T. Bártek, J. Miškov\& J. Švelch (Eds.), New Perspectives on Game Studies (pp. 109-124). Brno: Masaryk University.

Ferrari, S. (2013). eSport and the Human Body: Foundations for a Popular Aesthetics. In Proceedings of DiGRA 2013: DeFragging Game Studies, August 26-29. Atlanta, GA: DiGRA.

Groen, M. (2013). Exclusion and Inclusion of Women in E-sport and the Example of StarCraft: Wings of Liberty. In K. Mitgutsch, S. Huber, J. Wimmer, M. Wagner \& H. Rosenstingl (Eds.), Context Matters (pp. 235-240). Vienna: New Academic Press.

Guorui, Z. (2012). Bibliometric Analysis on E-Sports in China. In D. Zeng (Ed.) Advances in Computer Science and Engineering (pp. 111-118). New York, NY: Springer.

Hamari, J., \& Sjöblom, M. (2017). What is eSport and Why Do People Watch It? Internet Research, 27(2). 
Hamilton, W.A., Kerne, A., \& Robbins, T. (2012). High-Performance Pen + Touch Modality Interactions: A Real-Time Strategy Game eSports Context. In UIST'12 (pp. 309-318),7-10 October. New York: ACM.

Hebbel-Seeger, A. (2012). The Relationship Between Real Sports and Digital Adaptation in E-sport Gaming. International Journal of Sports Marketing \& Sponsorship, 13(2), 132-143.

Hemphill, D. (2005). Cybersport. Journal of the Philosophy of Sport, 32(2), 195-207.

Hemphill, D. (2015). Cybersport. In C. Torres (Ed.), The Bloomsbury Companion to the Philosophy of Sport (pp. 346348). Sydney, Australia: Bloomsbury.

Hewitt, E. (2014). Will ESports Ever Become Widely Accepted as Official Sports and How Will They Affect the Way We Entertain Ourselves If They Do? In J. Sharpe \& R. Self (Eds.), Computers for Everyone (pp. 81-83). Derby: University of Derby.

Holden, J.T., Rodenberg, R.M., \& Kaburakis, A. (2017). Esports Corruption: Gambling, Doping, and Global Governance. Forthcoming in the Maryland Journal of International Law.

Hollis, K. (2015). Time to Be Grown-Ups about Video Gaming: The Rising Esports Industry and the Need for Regulation. Arizona Law Review, 57, 823-847.

Holt, J. (2016). Virtual Domains for Sports and Games. Sport, Ethics, and Philosophy, 10(1), 5-13.

Huhh, J. (2008). Culture and Business of PC Bangs in Korea. Games and Culture, 3(1), 26-37.

Hutchins, B. (2008). Signs of Meta-Change in Second Modernity: The Growth of e-Sport and the World Cyber Games. New Media \& Society, 10(6), 851-869.

Hyland, D. (1990). Philosophy of Sport. York: Paragon House.

Jin, D.Y. (2010). Korea's Online Gaming Empire. Cambridge, MA: The MIT Press.

Jonasson, K. \& Thiborg, J. (2010). Electronic Sport and Its Impact on Future Sport. Sport in Society, 13(2), $287-299$.

Kari, T., \& Karhulahti, V. (2016). Do E-Athletes Move? A Study on Training and Physical Exercise in Elite E-Sports. International Journal of Gaming and Computer-Mediated Simulations, 8(4), pp. 53-66.

Karhulahti, V. (2016). Prank, Troll, Gross and Gore: Performance Issues in Esport Live-Streaming. In Proceedings of the First International Joint Conference of DiGRA and FDG, 1-5 August 2016. Dundee, Scotland: Digital Games Research Association and Society for the Advancement of the Science of Digital Games.

Kauweloa, S., \& Winter, J. (2016). Collegiate E-sports as Work or Play. In Proceedings of the First International Joint Conference of DiGRA and FDG, 1-5 August 2016. Dundee, Scotland: Digital Games Research Association and Society for the Advancement of the Science of Digital Games.

Korean Creative Content Agency. (2013). White Paper on Korean Games 2013. Seoul: Korea Creative Content Agency. Kim, Y. (2013). A Study of Wellness Core Technology and E-Sports. In IT Convergence and Security Proceedings (pp. 1-3), 14-16 December. Piscataway, NJ: IEEE.

Kim, Y.J., Choi, M.J., \& Cha, Y.S. (2012). A Study on the Impact of E-sports Participation by Students with Mental Retardation on Their Self-Confidence and Social Skills. In Ubiquitous and Future Networks Conference Proceedings (pp. 471-475), 1-6 July. Piscataway, NJ: IEEE.

Kushner, D. (2004). Masters of Doom: How Two Guys Created an Empire and Transformed Pop Culture. New York, NY: Random House.

Lee, A. (2005). E-Sports as a Growing Industry. Research Report. Seoul: Samsung Economic Research Institute.

Lee, D., \& Schoenstedt, L.J. (2011). Comparison of eSports and Traditional Sports Consumption Motives. ICHPER-SD Journal of Research, 6(2), 39-44.

Lee, S., An, J., \& Lee, J. (2014). The Relationship between E-Sports Viewing Motives and Satisfaction: The Case of League of Legends. In J. Strouhal (Ed.), Proceedings of International Conference on Business, Management \& Corporate Social Responsibility (pp. 33-36), 14-15 February. Batam, Indonesia: ICEHM.

Lefever, K. (2012). New Media and Sport. The Hague: TMC Asser Press.

Lehdonvirta, V., \& Castronova, E. (2014). Virtual Economies: Design and Analysis. Cambridge, MA: The MIT Press. Ma, H., Wu, Y., \& Wu, X. (2013). Research on Essential Difference of E-Sport and Online Game. In D. Wenjiang (Ed.), Informatics and Management Science V (pp. 615-621). New York, NY: Springer.

Maric, J. (2011). Electronic Sport: How Pro-Gaming Negotiates Territorial Belonging and Gender. Platform: Journal of Media and Communication, ECREA Special Issue, 6-23.

Martončik, M. (2015). E-Sports: Playing Just for Fun or Playing to Satisfy Life Goals? Computers in Human Behavior, 48, 208-211. 
Mather, V., \& Carey, C. (2015, November 13). Russia Suspended from World Track and Field. The New York Times.Retrieved April 13, 2017, from https:/www.nytimes.com/2015/11/14/sports/russia-suspended-by-track-andfields-governing-body.html

McTee, M. (2014). E-Sports: More Than Just a Fad. 10 Oklahoma Journal of Law \& Technology, 70, pp. 1-27.

Mykles, C. (2016a). Riot's Renegades Investigation. Retrieved April 13, 2017, from https://www.youtube.com/watch?v=HXIcwyTutno

Mykles, C. (2016b). Unnamed document. Retrieved April 13, 2017, from https://www.scribd.com/document/319603736/Riot-Renegades-Investigation

Nagel, M. \&Sugishita, K. (2016). Esport: The Fastest Growing Segment of the "Sport” Industry. Sport \& Entertainment Review, 2(2), pp. 51-60.

Parshakov, P., \&Zavertiaeva, M.A. (2015). Success in eSports: Does Country Matter? SSRN. Retrieved April 13, 2017, from https://papers.ssrn.com/sol3/papers.cfm?abstract_id=2662343

Rambusch, J., Jakobsson, P., \&Pargman, D. (2007). Exploring E-sports: A Case Study of Gameplay in Counter-Strike. In Proceedings of DiGRA 2007 (pp. 157-164), September 24-28. Tokyo, Japan: DiGRA.

Riot Games. (2015). Competitive Ruling: Chris Badawi. Riot Games statement. Retrieved April 13, 2017, from http://2015.na.lolesports.com/articles/competitive-ruling-chris-badawi

Riot Games. (2016a). Competitive Ruling: Renegades and TDK.Riot Games statement. Retrieved April 13, 2017, from http://www.lolesports.com/en_US/articles/competitive-ruling-renegades-and-tdk

Riot Games. (2016b). The Indefinite Banning of Tyler1.Riot Games statement. Retrieved April 13, 2017, from http://boards.na.leagueoflegends.com/en/c/player-behavior-moderation/8a75KeUR-the-indefinite-banning-of-tyler1

Rothman, J. (2013). Response: E-Sports as a Prism for the Role of Evolving Technology in Intellectual Property. University of Pennsylvania Law Review Online, 161, 317-329.

Ruiz, R. (2016, June 17). Russia's Track and Field Team Barred from Rio Olympics. The New York Times. Retrieved April 13, 2017, fromhttp://www.nytimes.com/2016/06/18/sports/olympics/russia-barred-rio-summer-olympicsdoping.html?_r=0

Ryzhov, I., Tariq, A., \& Powell, W. (2011). May the Best Man Win: Simulation Optimization for Match-Making in Esports. In S. Jain, R. Creasey, J. Himmelspach, K.P. White \& M. Fu (Eds.), Proceedings of the Winter Simulation Conference (pp. 4239-4250), 11-14 December. Piscataway, NJ: IEEE.

Seo, Y. (2013). Electronic sports: A New Marketing Landscape of the Experience Economy. Journal of Marketing Management, 29(13-14), 1542-1560.

Seo, Y. (2016). Professionalized Consumption and Identity Transformations in the Field of eSports. Journal of Business Research, 69(1), 264-272.

Seo, Y., \& Jung, S. (2014). Beyond Solitary Play in Computer Games: The Social Practices of eSports. Journal of Consumer Culture.

Sport Accord. (2016). Organization homepage. Retrieved April 13, 2017, from

http://www.sportaccord.com/about/membership/definition-of-sport.php

Stein, V., \& Scholz, T. (2014). The Intercultural Challenge of Building the European eSports League for Video Gaming. In C. Barmeyer \& P. Franklin (Eds.), Case Studies in Intercultural Management: Achieving Synergy from Diversity (pp. 1-13). Basingstoke: Palgrave Macmillan.

Szablewicz, M. (2011). From Addicts to Athletes: Participation in the Discursive Construction of Digital Games in Urban China. In S. Fragoso (Ed.), Selected Papers of Internet Research 12.0 (pp. 1-21). Seattle, WA: Association of Internet Researchers.

Szablewicz, M. (2016). A Realm of Mere Representation? “Live” E-Sports Spectacles and the Crafting of China's Digital Gaming Image. Games and Culture, 11(3), 256-274.

Taylor, N. (2009). Cheerleaders, Booth Babes, Halo Hoes: Pro-Gaming, Gender and Jobs for the Boys. Digital Creativity, 20(4), 239-252.

Taylor, N. (2011). Play Globally, Act Locally: The Standardization of Pro Halo 3 Gaming. International Journal of Gender, Science and Technology, 3(1), 228-242.

Taylor, N. (2012). "A Silent Team is a Dead Team": Communicative Norms in Team-Based Halo 3 Play. In G. Voorhees (Ed.), Guns, Grenades and Grunts: First Person Shooter Games (pp. 251-275). New York, NY: Continuum.

Taylor, N. (2015). Professional Gaming. In R. Mansell \& P. Ang (Eds.), The International Encyclopedia of Digital Communication and Society (pp. 1-4). Hoboken, NJ: John Wiley \& Sons.

Taylor, T.L. (2012). Raising the Stakes: E-Sports and the Professionalization of Computer Gaming. Cambridge, MA: The MIT Press. 
Trammell, A. (2010). Magic: The Gathering in Material and Virtual Space: An Ethnographic Approach Toward Understanding Players Who Dislike Online Play. In Meaningful Play 2010 proceedings (pp. 1-21). Retrieved April 13, 2017, from http://meaningfulplay.msu.edu/proceedings2010/mp2010_paper_42.pdf

Van Hilvoorde, I. (2016). Sport and Play in a Digital World. Sport, Ethics and Philosophy, 10(1), 1-4.

Van Hilvoorde, I., \& Pot, N. (2016). Embodiment and Fundamental Motor Skills in eSports. Sport, Ethics and Philosophy, 10(1), 14-27.

Wagner, M. (2006). On the Scientific Relevance of eSport. In Proceedings of the 2006 International Conference on Internet Computing and Conference on Computer Game Development. Electronic version (pp. 1-4). Athens, GA: CSREA Press.

Wagner, M. (2007). Competing in MetagameGamespace: eSport as the First Professionalized Computer Metagames. In F. von Borries, S.P. Walz, M. Bèottger, D. Davidson, H. Kelley \& J. Kücklich (Eds.), Space Time Play (pp. 182-185). New York, NY: Springer.

Weiss, P. (1969). Sport: A Philosophical Inquiry. Carbondale, IL: Southern Illinois University.

Weiss, T. (2008). Cultural Influences on Hedonic Adoption Behavior: Propositions Regarding the Adoption of Competitive Video and Computer Online Gaming. In Proceedings of the SIG-DIGIT Workshop 2008. Electronic Version. Retrieved April 13, 2017, from http://aisel.aisnet.org/cgi/viewcontent.cgi?article=1006\&context=digit2008

Weiss, T. (2011). Fulfilling the Needs of eSports Consumers: A Uses and Gratifications Perspective. In Proceedings of the $24^{\text {th }}$ Bled eConference (pp. 572-580), 12-15 June. Bled, Slovenia: University of Maribor.

Wimmer, J. (2012). Digital Game Culture(s) as Prototype(s) of Mediatization and Commercialization of Society. In J. Fromme \& A. Unger (Eds.), Computer Games and New Media Cultures: A Handbook of Digital Game Studies (pp. 525-540). New York, NY: Springer.

Witkowski, E. (2012a). On the Digital Playing Field: How We "Do Sport" With Networked Computer Games. Games and Culture, 7(5), 349-374.

Witkowski, E. (2012b). Inside the Huddle: The Phenomenology and Sociology of Team Play in Networked Computer Games. Doctoral Dissertation, IT University of Copenhagen, Copenhagen, Denmark.

Wizards of the Coast. (2016). Magic: The Gathering ${ }^{\circledR}$ Tournament Rules. Public Document. Retrieved April 13, 2017, from https://wpn.wizards.com/sites/wpn/files/attachements/mtg_mtr_22jan16_en.pdf

Wolf, J. (2016). Renegades, Riot and the Danger of Absolute Power. ESPN. Retrieved April 13, 2017, from http://espn.go.com/esports/story/_id/17132668/renegades-riot-danger-absolute-power

World Anti-Doping Agency. (2015). The Independent Commission Report. R. Pound, R. McLaren \& G. Younger (Eds.). Montreal, Canada: World Anti-Doping Agency. Retrieved April 13, 2017, from $\underline{\text { https://static.rasset.ie/documents/sport/wada-russia-report.pdf }}$

AUTHOR'S ADDRESS: $\quad$ Veli-Matti Karhulahti

University of Turku

Department of Media Studies

20014 Turunyliopisto, Finland

E-mail: vmmkar@utu.fi

Received: 28 January 2017; Accepted: 15 March 2017 